\title{
Chapter 11 \\ Mathematics Learning: Perceptions Toward the Design of a Website Based on a Fun Computational Thinking-Based Knowledge Management Framework
}

\author{
Chien-Sing Lee and Pei-Yee Chan
}

\begin{abstract}
Mathematics is core to many scientific disciplines as it trains the mind in representation, logic, and various data manipulations. Mathematics is thus the power of reasoning, creativity, problem-solving, and effective communication skills. Mathematics can, however, be difficult to learn if interest and teaching-learning approaches do not link theory with real-world problems. Hence, the goal of this study is to enhance the learning of Mathematics using a multi-stakeholder, fun Computational Thinking (CT)-Knowledge Management (KM) framework. We hypothesize that this framework will help improve stakeholders' perceptions toward the learning of Mathematics and CT as elements of fun can transform knowledge more productively. Brennan and Resnick's (2012) CT involves three aspects: computational perspective, computational practice, and computational concepts. These are implemented in different ways to suit different contexts and needs. Furthermore, KM encourages knowledge creation and sharing in order to produce more innovative outcomes. The findings of this study indicate that there is an increased positive perception toward the Website's objectives, usefulness, and ease of use. We hope that by enabling students to create, share, and discuss fun-based problems for others to solve, they will gain confidence in their own understanding of and creativity in problem-solving.
\end{abstract}

Keywords Computational thinking $\cdot$ Computational perspective $\cdot$ Computational practice $\cdot$ Computational concepts $\cdot$ Fun knowledge management framework

\subsection{Introduction}

The application of computational thinking (CT) can be found in most institutions and agencies today. Wing (2006) defines CT as "a universally applicable attitude and skill set everyone, not just computer scientists, would be eager to learn and use." With

C.-S. Lee · P.-Y. Chan $(\bowtie)$

Department of Computing and Information Systems, Sunway University, Petaling Jaya, Malaysia e-mail: chanpy95@hotmail.com; 13018197@imail.sunway.edu.my

C.-S. Lee

e-mail: chiensingl@ sunway.edu.my; csleester@gmail.com

(C) The Author(s) 2019

S.-C. Kong and H. Abelson (eds.), Computational Thinking Education,

https://doi.org/10.1007/978-981-13-6528-7_11 
regard to attitude, CT encourages an open mindset challenging boundaries and pursuing refinements. An open mindset corresponds with (a) reformulating a seemingly difficult problem into one solution familiar to us, either by reduction, transformation, or simulation; (b) choosing an appropriate representation of a problem or modeling the relevant aspects of a problem; (c) thinking recursively; and (d) processing alternatives and constraints simultaneously. These further point toward two key computer science concepts, i.e., decomposition and abstraction. Consequently, CT enables better identification of data patterns, better understanding and solving of problems, systems and human behavior, and more effective analysis.

Brennan and Resnick (2012) aim to reach out to the masses, through CT. Hence, they have simplified CT into three aspects: (a) computational perspectives, (b) computational practice, and (c) computational concepts. The Computational Thinking (CT) course website (2017) supports Wing's (2006) and Brennan and Resnick's (2012) propositions, and regards CT as comprising of four components: (a) decomposition, (b) pattern recognition, (c) algorithmic thinking, and (d) generalization.

To us, CT is a means to an end, whereby it can help make the teaching of programming more effective. CT is also an end in itself due to the progressive developmental nature of learning. We adopt the four CT components at the CT course website for this study as the website integrates propositions by eminent founders and practitioners.

\subsubsection{Problem}

Knowledge of Mathematics is essential in everyday life. From the moment, we wake up in the morning to the minute we go to bed, we depend on our understanding of and capability to perform simple Mathematics-based tasks. Mathematics hones the power of reasoning and problem-solving, leading to better clarity in communication skills and higher creative possibility (Chan, 2010; Snalune, 2015; Biswas, 2015; Kong, 2019).

Our research interest focuses on the use of Mathematics to teach CT skills in a fun way. Mathematics is closely linked to CT as it involves a pattern recognition of a problem structure and variables that can be instantiated with different values, such as decomposition, to enable modularity and easier problem-solving; algorithm design, due to its emphasis on logical reasoning; and generalization, i.e., from multiple examples to formulation of principles. Thus, if CT can be used to find the best means of solving problems, then more creative solutions can be ideated and found to overcome difficulties.

Furthermore, increasingly, children are spending much time on the Internet and video games, even violent ones. The American Academy of Child and Adolescent Psychiatry (2015) points out that video game addiction can cause mental health and social problems to children since most of their time will be spent indoors playing online/video games. Furthermore, playing video games for long hours can affect academic performance since students will have problems focusing in class and interacting with others. Christopher (2015) confirms that even when interacting with 
others, they tend to only discuss video games. As time passes, their social communication will cease and they will have problems communicating with members of society in general.

Considering the benefits of learning Mathematics and CT skills, it is proposed that children's interest should be diverted from unhealthy video games to more educational, Mathematics-based games. Furthermore, if we can make learning more fun and enjoyable, we can incorporate Knowledge Management to enhance collaborative learning.

\subsubsection{Objectives}

An earlier study by Lee, Wong, and Ee (2017) use an object-oriented gamification approach to improve students' Mathematical and CT skills. The target students in the study are those studying in university. In this study, our framework adopts an inquiry-based student-centered learning framework, with primary school students (Primary 1-3) as the target users.

Student-centered learning (Table 11.1) supports the use of inquiry approaches such as games. Knowledge Management (KM) approaches complement such inquiry as KM involves knowledge acquisition, sharing, creation, and dissemination. These provide a structure to knowledge-building and collaborative learning.

Moreover, in Kong's (2019) 11 case studies on teacher professional development, he found that for scalability of teaching practices, content and teacher development models need to be developed from the perspective of a multi-stakeholder partnership. Subsequently, principles can serve as top-down strategies to be tested in classrooms, where successful patterns of e-learning can be identified in the long run to enrich students' and teachers' theoretical and practical understanding. Hence, a community approach is adopted in this study, involving parents, community members, and young children, since Primary 1-3 students are still very young and need motivation and support from their parents and peers/community.

In addition, elements of fun are crucial to the very young. Abelson's (2012) reconstructible computational media is one of the early works of fun visual programming. Eventually, fun-based Scratch (Resnick, 2007) came about. Fun in this study is game-based and refers to Koster's (2004) theory of fun for game design. Koster notes that game design requires pattern recognition, and variations from these patterns and inherent game mechanics will pose interesting challenges/inquiries to players.

As such, in this study, we enable students to tinker with Mathematical concepts and practice in various ways to refine their computational perspectives. We hypothesize that designing using Brennan and Resnick's (2012) CT, Ventakesh and Davis' (2000) Technology Acceptance Model, and a fun KM approach will improve stakeholders' perception toward (a) the importance of learning mathematical concepts; (b) the mastery of Mathematical (curricular) knowledge and skills; (c) the mastery of critical thinking and communication skills; and (d) online learning. 
Table 11.1 Characteristics of student-centered learning which supports the KM approach

\begin{tabular}{|c|c|c|}
\hline $\begin{array}{l}\text { Categories of classroom } \\
\text { practice. }\end{array}$ & Teacher-centered (TC) & Student-centered (SC) \\
\hline & $\begin{array}{l}\text { Teacher-directed } \\
\text { Primarily didactic }\end{array}$ & $\begin{array}{l}\begin{array}{l}\text { Student-directed } \\
\text { Primarily interactive }\end{array} \\
\end{array}$ \\
\hline Teacher role & $\begin{array}{l}\square \text { Present information } \\
\square \text { Manage classroom }\end{array}$ & $\begin{array}{l}\text { Guide discovery } \\
\square \text { Model active learning } \\
\square \quad \text { Collaborator (sometimes learner) }\end{array}$ \\
\hline Student role & $\begin{array}{l}\square \text { Store, remember information } \\
\square \text { Complete tasks individually }\end{array}$ & $\begin{array}{l}\square \text { Create knowledge } \\
\square \text { Collaborator (sometimes expert) }\end{array}$ \\
\hline Curricular characteristics & $\begin{array}{l}\text { Breadth - focused on externally mandated } \\
\text { curriculum } \\
\square \text { Focus on standards } \\
\square \text { Fact retention } \\
\square \quad \begin{array}{l}\text { Fragmented knowledge and disciplinary } \\
\text { separation }\end{array} \\
\end{array}$ & $\begin{array}{l}\square \quad \text { Depth - focused on student interests } \\
\square \text { Focus on understanding of complex ideas } \\
\square \text { Application of knowledge to authentic } \\
\text { problems } \\
\square \quad \text { Integrated multidisciplinary themes }\end{array}$ \\
\hline Classroom social organization & \begin{tabular}{|ll} 
口 & Independent learning \\
․ & Individual responsibility for entire task
\end{tabular} & $\begin{array}{l}\square \text { Collaborative learning } \\
\square \text { Social distribution of thinking }\end{array}$ \\
\hline Assessment practices & $\begin{array}{|ll|}\text { 口 } & \text { Fact retention } \\
\square & \text { Product oriented } \\
\square & \text { Traditional tests } \\
\square & \text { Norm referenced } \\
\square & \text { Teacher-led assessment }\end{array}$ & $\begin{array}{l}\square \text { Applied knowledge } \\
\square \text { Process oriented } \\
\square \text { Alternative measures } \\
\square \text { Criterion referenced } \\
\square \quad \text { Self-assessment and reflection }\end{array}$ \\
\hline \begin{tabular}{|l|} 
Technology role \\
\end{tabular} & \begin{tabular}{|ll}
$\square$ & Drill and practice \\
$\square$ & Direct instruction \\
$\square$ & Programming
\end{tabular} & $\begin{array}{l}\square \text { Exploration and knowledge construction } \\
\square \text { Communication (collaboration, information } \\
\text { access, expression) } \\
\square \text { Tool for writing, data analysis, problem- } \\
\text { solving }\end{array}$ \\
\hline Technology content & \begin{tabular}{|ll} 
& Basic computer literacy \\
$\square$ & Skills taught in isolation
\end{tabular} & $\begin{array}{l}\square \text { Emphasis on thinking skills } \\
\square \text { Skills taught and leamed in context and } \\
\text { application }\end{array}$ \\
\hline
\end{tabular}

Source Ertmer, Ottenbreit-Leftwich, Sadik, Sendurur, and Sendurur (2012)

This chapter is presented in the following order: literature review, methodology, game design, user testing, findings, significance, and finally conclusions.

\subsection{Literature Review}

\subsubsection{Computational Thinking (CT)}

Computing involves not only programming and practicing computing skills but also recursive thinking, model matching, and compositional reasoning. These will enhance algorithmic thinking, parallel thinking, and practical thinking as well. As a result, through $\mathrm{CT}$, the learner develops problem-solving processes and dispositions. These are very important to the advancement of computer systems and functions, especially analysis and design as well as justifications to problems and solutions (Togyer \& Wing, 2017).

CT shows how individual knowledge and skills gained from computing subjects can bring positive impact to society. The CT course website (2017) provides some examples. In Economics, one can find cycle patterns in the rise and fall of a country's 
economy; in Mathematics, the steps to solve a calculus problem; in Chemistry, the principles for ionization. Hence, people who understand and have knowledge of CT in their studies will see the correlation between theoretical subjects and the environment (between indoor/formal learning and outdoor/informal learning).

Abelson (2012) further points out that for CT to grow beyond re-constructible computational media, it needs to be complemented by computational values which promote open access. This has partly led to the popularity of open-source movements. Consequently, CT's objective of building individual capability and creativity (Weintrop, Holbert, Horn, \& Wilensky, 2016) and the open-source movements have influenced many professions and computer science curricula in developing countries.

\subsubsection{Game-Based Learning and Gamification}

According to Kazimoglu, Kiernan, Bacon, and MacKinnon (2012), digital gameplay involves thinking of the correct solution for the players to move on to the next level. This motivation has driven the video gaming industry to constantly move forward. According to the global game-based learning market, the world profits for gamebased learning products reached $\$ 2.6$ billion in 2013 and are expected to gain a profit of $\$ 7.3$ billion by 2021. In 2016, a total of $\$ 99.6$ billion in revenue was earned from worldwide games, which led to an $8.5 \%$ increment compared to the revenue earned in 2015 (Adkins, 2016).

There are different types of games including educational games, adventure games, action games, and role-playing games. Table 11.2 presents some of the benefits of these games mentioned in prior literature.

\subsubsection{Knowledge Management}

KM revolves around knowledge acquisition, sharing, translation/transformation, and dissemination (Nonaka \& Takeuchi, 1991; Frappaolo, 2006; Maier, 2010; Jashapara, 2011). This approach is chosen as we would like the students to follow the KM cycle and finally create their own games using Scratch.

\subsection{Methodology}

First of all, the Software Development Life Cycle (SDLC) is used to design the game and to ensure the quality of the online game portal. For user requirements, we have carried out a questionnaire to survey students and parents' opinion and preferences with regard to our objectives and the proposed Website portal. Next, we have designed and developed the Website according to their opinion and preferences 
Table 11.2 Summary matrix of conference and journal article reviews

\begin{tabular}{l|l|l|l|l}
\hline Functions/Journal & $\begin{array}{l}\text { The } \\
\text { educational } \\
\text { benefits of } \\
\text { video games }\end{array}$ & $\begin{array}{l}\text { Effects of } \\
\text { game } \\
\text { technology on } \\
\text { elementary } \\
\text { student } \\
\text { learning in } \\
\text { mathematics }\end{array}$ & $\begin{array}{l}\text { Playing video } \\
\text { games could } \\
\text { boost } \\
\text { children's } \\
\text { intelligence } \\
\text { (but Facebook } \\
\text { will ruin their } \\
\text { school grades) }\end{array}$ & $\begin{array}{l}\text { A surprising } \\
\text { new study on } \\
\text { how video } \\
\text { games impact } \\
\text { children }\end{array}$ \\
\hline $\begin{array}{l}\text { Improve } \\
\text { problem-solving skills }\end{array}$ & + & + & + & + \\
\hline $\begin{array}{l}\text { Increase task variety } \\
\text { Develop and improve } \\
\text { social skills }\end{array}$ & & + & + & + \\
\hline $\begin{array}{l}\text { Improve technology } \\
\text { and education skills }\end{array}$ & + & + & + & + \\
\hline $\begin{array}{l}\text { Sharpen and apply } \\
\text { knowledge in school }\end{array}$ & + & + & + & + \\
\hline
\end{tabular}

and the KM cycle. Stakeholders' involvement is critical and as such, their feedback weighed heavily on our design and development. Consequently, we have adopted agile methodology to design and develop incrementally to cater to user feedback. For design and analysis, ease of use and usefulness, the two key assessment metrics of the Technology Acceptance Model (Ventakesh \& Davis, 2000) are also applied in alpha and beta testings.

\subsubsection{Website Component Design Based on Computational Thinking (CT)}

We designed the Website portal based on the recommendations of Wing (2006), Brennan and Resnick (2012), and the CT course website based on the four main CT concepts: (a) dividing the processes into parts (decomposition); (b) knowing and finding the correct patterns for problem-solving (pattern recognition); (c) writing algorithms for the user to solve problems (algorithm design); and (d) determining the rules and principles of a particular subject (abstraction/generalization).

The mapping of the Website components to the CT concepts is in Fig. 11.1.

Website aims at progressive and incremental improvement, corresponding to Bloom's taxonomy. The most basic Mathematics concept is number counting. Hence, the initial level is to present odd and even numbers to familiarize students with numeric values, and at the higher level is the concept of interval.

From numeric values, pattern recognition is developed by progressing through (a) multiple examples in worksheets and (b) Scratch programming. The worksheets, 


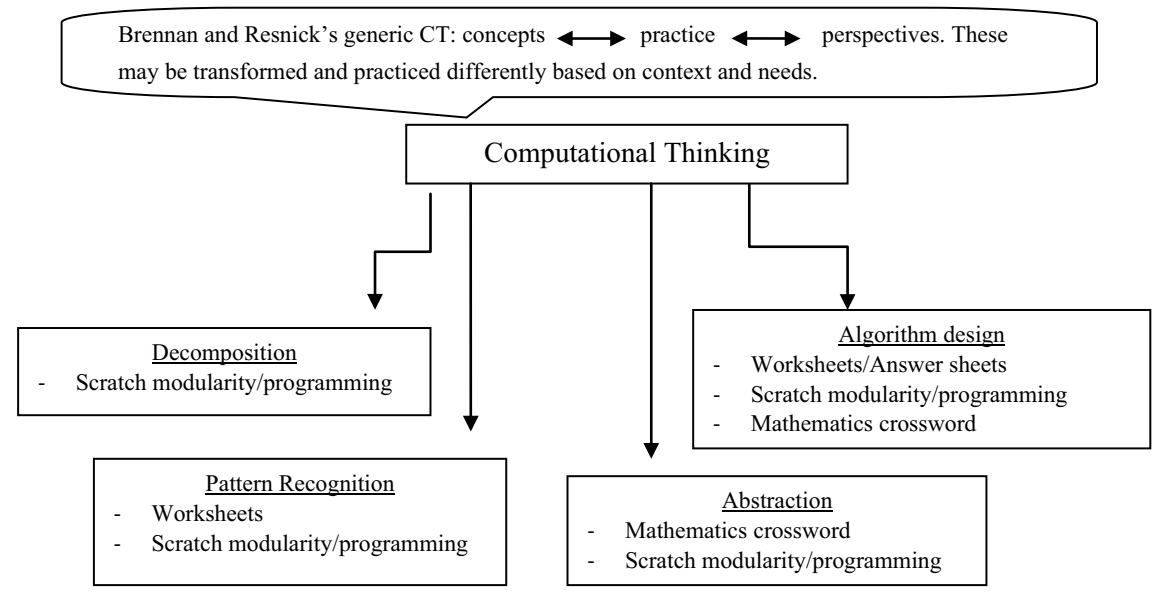

Fig. 11.1 Mapping of website components to CT concepts

which are of different difficulty levels, enable students to not only go through the steps for each concept exercise but also to inductively realize that many problems are similar. In Scratch programming, building blocks can be reused and remixed for different fun outcomes.

Next is algorithm design and later, abstraction. For solution steps (algorithm design), diverse formulas/methods of solving problems can lead to the same answer. We choose a Mathematics crossword puzzle because it enables students to identify different solutions to the same problem. This leads to generalizing.

Due to the iterative nature of agile-based SDLC methodology, the sections below present the progression/iterative design process and user testings, which have led to the subsequent versions of the Website.

\subsection{Pilot Test: Preliminary Design and Analysis}

In the pilot test, a total of 27 responses from different age groups are gathered through a questionnaire to identify their opinion and preferences. Questions are scored on a range of one (not important) to five (most important). There are five different age groups: children (6 years old to 12 years old), teenagers (13 years old to 19 years old), young adults (20 years old to 35 years old), adults (36 years old to 59 years old), and senior citizens (60 years old and above). The five different age groups are categorized as such to derive a more holistic understanding of factors, which would sustain both learning and future system development.

Young adults make up $40.7 \%$ of the sample, whereas adults only make up $7.4 \%$. There are $18.6 \%$ more female respondents compared to male respondents. During 


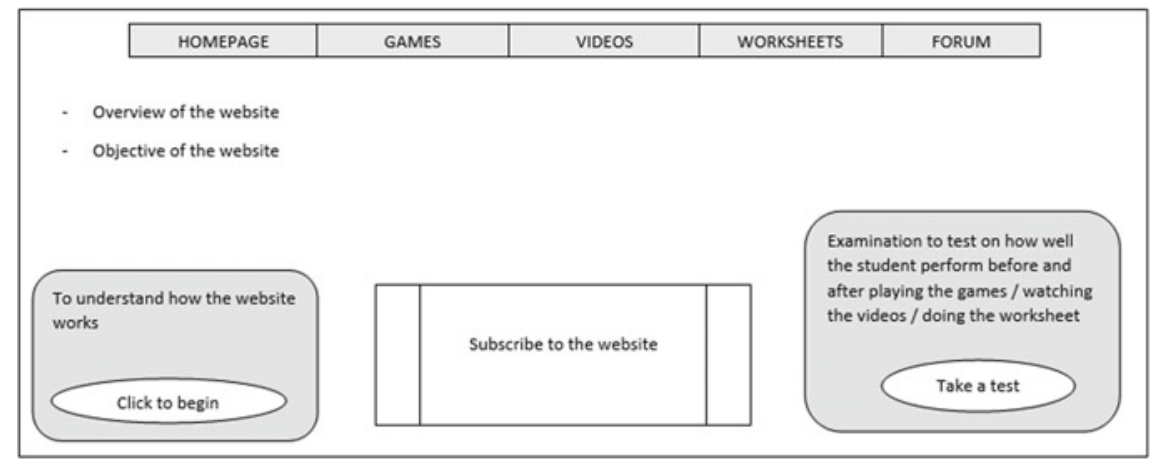

Fig. 11.2 Website's wireframe (main page)

the pilot test, the participants are shown the Website's main page in wireframe format (Fig. 11.2), followed by the survey questions.

A summary of the responses received from the participants is presented in Table 11.3. The feedback obtained is used to further refine the proposed Website portal.

Table 11.3 Summary of the responses from pilot test participants

\begin{tabular}{|c|c|}
\hline Question & Answers \\
\hline $\begin{array}{l}\text { How long does the respondent usually spend } \\
\text { time studying online? }\end{array}$ & $\begin{array}{l}\text { - More than two hours }(37 \%) \\
\text { - Two hours }(22.2 \%) \\
\text { - One hour }(22.2 \%)\end{array}$ \\
\hline Importance of Mathematical concepts & - Very important (52\%) \\
\hline $\begin{array}{l}\text { Importance of understanding the use of } \\
\text { Mathematics in the real world }\end{array}$ & - Important (44\%) \\
\hline $\begin{array}{l}\text { Whether they agree that learning Mathematics } \\
\text { through games would help improve student's } \\
\text { performance }\end{array}$ & $\begin{array}{l}\text { - Agree }(92.6 \%) \\
\text { - Disagree }(7.4 \%)\end{array}$ \\
\hline $\begin{array}{l}\text { Whether they agree the best way for students to } \\
\text { learn is to find solutions to problems on their } \\
\text { own }\end{array}$ & $\begin{array}{l}\text { - Agree }(85.2 \%) \text { : If they find the solution, } \\
\text { they will get to experience different ways } \\
\text { of tackling problems. This can help them } \\
\text { gain extra knowledge and is one of the } \\
\text { ways to train them to be independent } \\
\text { - Disagree }(14.8 \%)\end{array}$ \\
\hline Motivators in learning & $\begin{array}{l}\text { - Creativity and discussion (63\%), reward } \\
(51.9 \%) \text {, feedback }(44.4 \%)\end{array}$ \\
\hline Purpose for having an educational game & $\begin{array}{l}\text { - Extra revision }(44.4 \%) \\
\text { - Reward and group work }(44.4 \%)\end{array}$ \\
\hline
\end{tabular}




\subsection{Alpha Testing: Design and Development}

The purpose of the alpha testing is twofold: (a) to ensure that all functions in the Website portal are working; and (b) to obtain user feedback to refine the system. Users can have an overview of the Website portal on the homepage (Fig. 11.3). They can also access the Mathematics test to determine and improve their level of Mathematics.

Worksheets are divided according to the students' age group to help narrow down the worksheets to the targeted age group:

- For Primary 1, basic Mathematics equations for users are included to familiarize them with numbers and equations.

- For Primary 2, the multiplication timetable and basic problem-solving skills are included.

- For Primary 3, the focus is mainly on money value and problem-solving skills.

Answer sheets are provided for each worksheet so that users can check their performance and see different methods of solving a problem. Figures 11.4, 11.5, and 11.6 are sample screenshots of the questions and answers.

A forum page for parents and students is also included in the Website to enable discussion, information sharing, and knowledge exchange. Moreover, the forum can be used to help users improve their social skills. The game created using Scratch is found in "Fun Time".

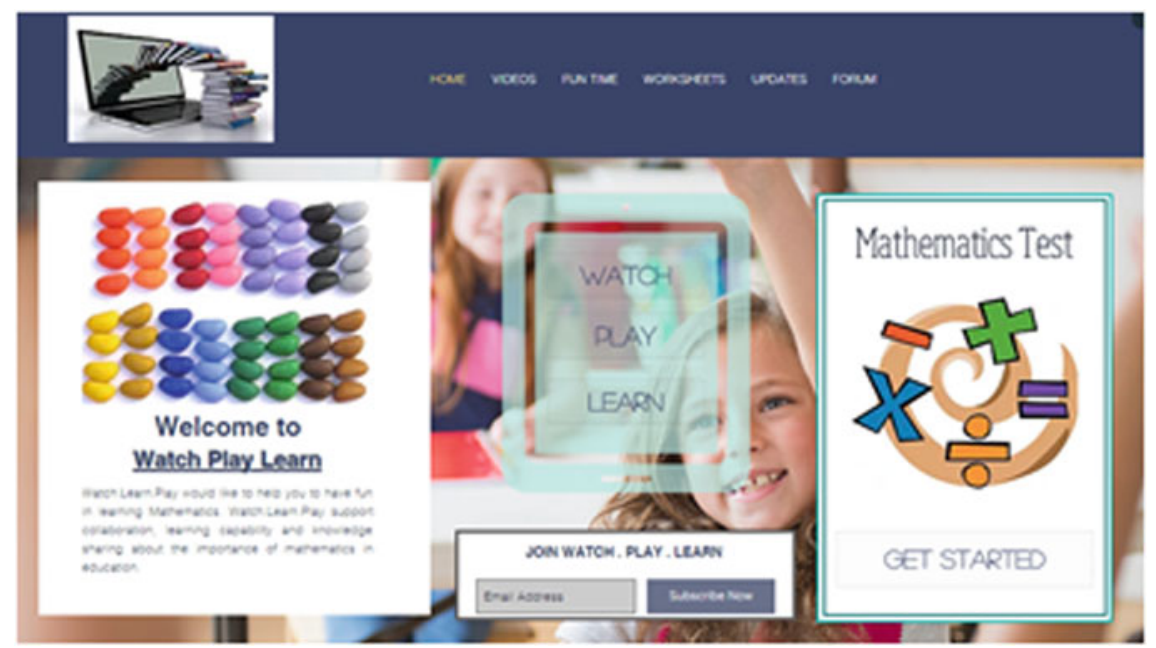

Fig. 11.3 Website homepage 


\begin{tabular}{|l|l|}
\hline \multicolumn{1}{|c|}{ Question } & \multicolumn{1}{c|}{ Working } \\
\hline Write the following numerals in words. & $\begin{array}{l}\text { i) Forty-five } \\
\text { i) } 45\end{array}$ \\
ii) Ninety-nine \\
\hline Answer True or False for the following & \\
questions. & i) True \\
i) 5 is less than 10 & ii) True \\
ii) 8 is greater than 7 & iii) False \\
iii) 2 is greater than 4 & iv) True \\
iv) 99 is less than 999 &
\end{tabular}

Fig. 11.4 Primary 1 sample worksheet (numeric value, comparison)

\begin{tabular}{|l|l|}
\hline \multicolumn{1}{|c|}{ Question } & Working \\
\hline $\begin{array}{l}\text { Jeremy has } 90 \text { marbles. He gave John } 45 \\
\text { marbles. How many marbles does he left? }\end{array}$ & Jeremy left 45 marbles. \\
\hline $\begin{array}{l}\text { There are } 12 \text { chocolates in } 3 \text { boxes. How many } \\
\text { chocolates are there in a box? }\end{array}$ & $12 \div 3=4$ \\
\hline
\end{tabular}

Fig. 11.5 Primary 2 sample worksheet (number value, pattern recognition with regard to numbers, numeric value, and operators)

\subsubsection{Alpha User Testing}

For the alpha user testing, a total of 31 responses from different age groups are collected. Similar to the pilot test, there are five categories of respondents. For the question regarding the importance of understanding Mathematics in the real word, $35.5 \%$ of them said that it is important. From the range of one (not important) to five (most important), none of them said that Mathematics is not important.

As for the overall rating of the Website, $16.1 \%$ of the respondents rate it as average, while most users $(61.3 \%)$ give it a rating of 4 . To further elicit user requirements/expectations, user feedback is compiled (Table 11.4) and considered for further testings. 


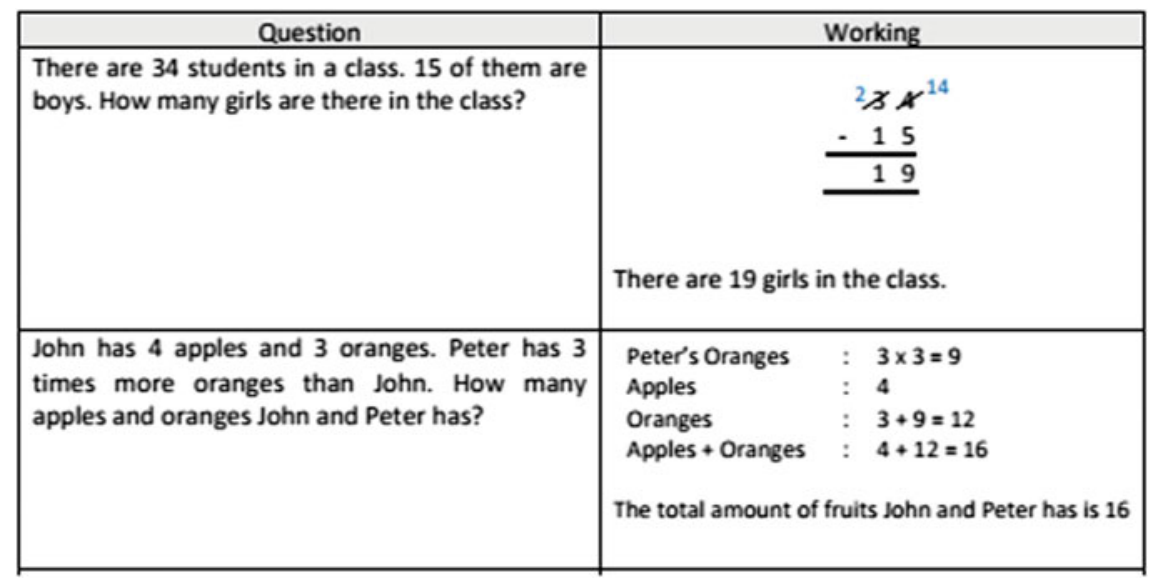

Fig. 11.6 Primary 3 sample worksheet (numeric value, pattern recognition with regard to numbers, numeric value, operators, and algorithm design)

Table 11.4 User's expectations

What do you expect from the website and game?

Keep up the good work!!

Critical thinking skills in solving Mathematical problems (2)

Knowledgeable and fun, enable the user to watch and learn with fun, something interesting

Improve design, strategy game

Add more things, more exercise, more worksheets and give answers, more pictures

\subsection{Beta Testing}

For the final evaluation process, the design is based on the alpha users' perceptions and experience. We first present the design for the game and then the Website. Users can select to start the game or to understand the game instructions. The voice narration for the game is downloaded from the Watson text-to-speech demo.

Once users start the game, a brief introduction is presented. There are four stages in this game. The first and second stages of the game require users to select all the colored balls containing even and odd numbers in order to proceed to the next level. As they proceed with the game, they would get points if they manage to answer the given questions correctly. Once users manage to complete all the stages, they are required to purchase the "tickets" with their points to watch the space videos as a reward. The reward can demonstrate to users that mastering Mathematical skills is key to earning points. Knowledge translation is involved when users apply Mathematical skills that they have learnt to identify the correct answers. 
(a)

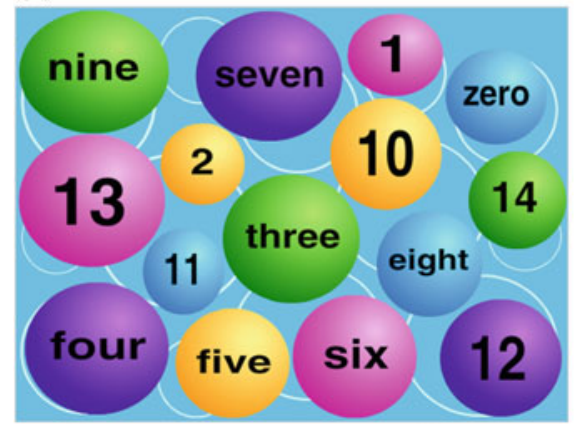

(b)

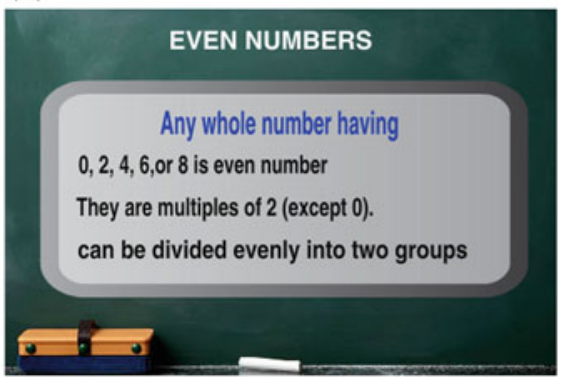

Fig. 11.7 a Even number game (number value), b even number clip (number value)
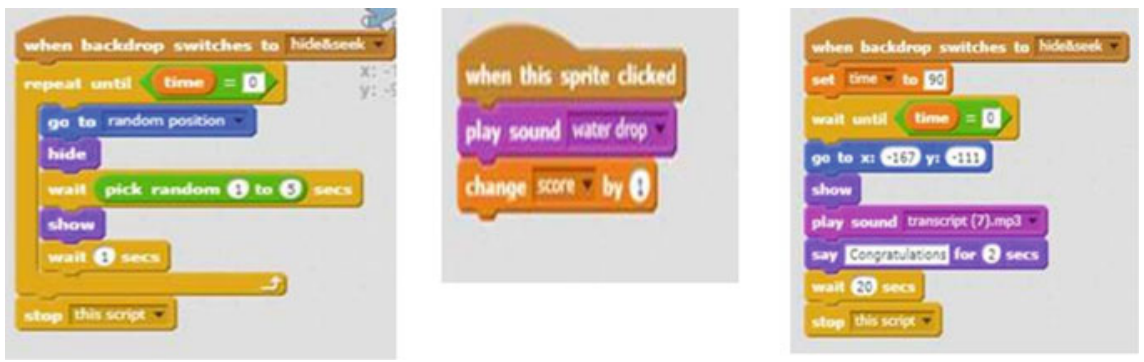

Fig. 11.8 Hide-and-seek code (object-orientation, decomposition, variables, behavior, values)

If users do not know what even and odd numbers are, they can watch a short clip explaining and teaching them what these numbers are. Figure 11.7a, b is sample screenshots of the even number game and clip.

Next is the game and/or reward using Scratch (Fig. 11.8). Students can manipulate the actions, variables, and values for different outcomes.

Figure 11.8 shows a hide-and-seek game developed in Scratch. The seeker is given 90 s to find the hider, who can hide at any random position. This game will be repeated until the time runs out. After a couple of seconds, the seeker will show up and start seeking the hider. If the seeker finds the hider at the $\mathrm{x}$ - and $\mathrm{y}$-coordinates (e.g., $-167,-111$ ), then the hider will be revealed and the user score will increase by 1 point. The word "Congratulations" will then be displayed to let the user feel a sense of achievement.

The variability in values enables users to manipulate the pace of the game, as well as the kinds of encouragement and sound effects they would like to include in the game. Water drop in this example may not be appropriate. So it may be the first value to be changed.

Finally, a Mathematics crossword puzzle enables users to click on the empty boxes within the crossword to fill in the answers. The purpose of the crossword is to show users that similar Mathematical functions such as addition and subtraction can 
Fig. 11.9 Mathematics crossword puzzle

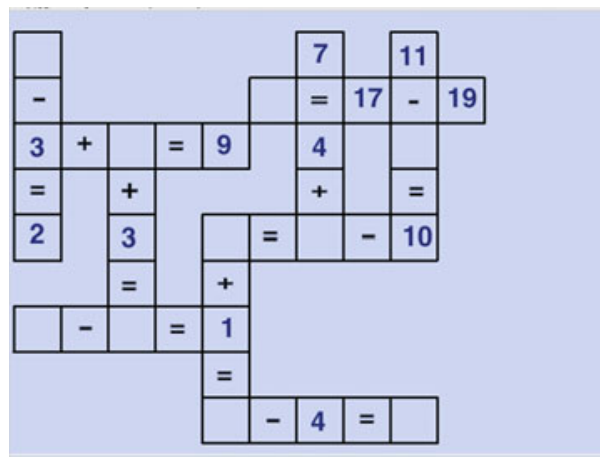

be found in different Mathematical equations, and that there are different components/methods to arrive at a solution. In Fig. 11.9, users have to think of the solution from multiple perspectives, simulating higher level algorithm design. For example, there are two ways to arrive at the total 10 . We hope that with practice, users will understand the link between algorithm design and numeric value, operators, and problem-solving.

Since we are trying to encourage learning in a community, a blog site enables posting of updates regarding the subject matter. The forum enables them to share ideas, knowledge, and problem-solving among users and their parents.

\subsection{Comparison Between Alpha-Beta User Testings}

For beta testing, a total of 30 responses from five different age groups are collected. The age groups include children ( 6 years old to 12 years old), teenagers ( 13 years old to 19 years old), young adults (20 years old to 35 years old), adults (36 years old to 59 years old), and senior citizens (60 years old and above). $56.7 \%$ of the respondents comprises the young adults and $26.7 \%$ of them are adults.

Table 11.5 shows the comparisons between the alpha- and beta testing results, while Table 11.6 presents user expectations for the future Website and game development. The Likert scale ranges from 1 (least important) to 5 (most important).

Although the perception outcomes are consistent and positive, the stakeholders mainly prefer simple designs and manageable exercises and games. Furthermore, users may find it challenging to find the solutions to problems all by themselves. Hence, adaptations in the sequence and choice of activities would be necessary. 


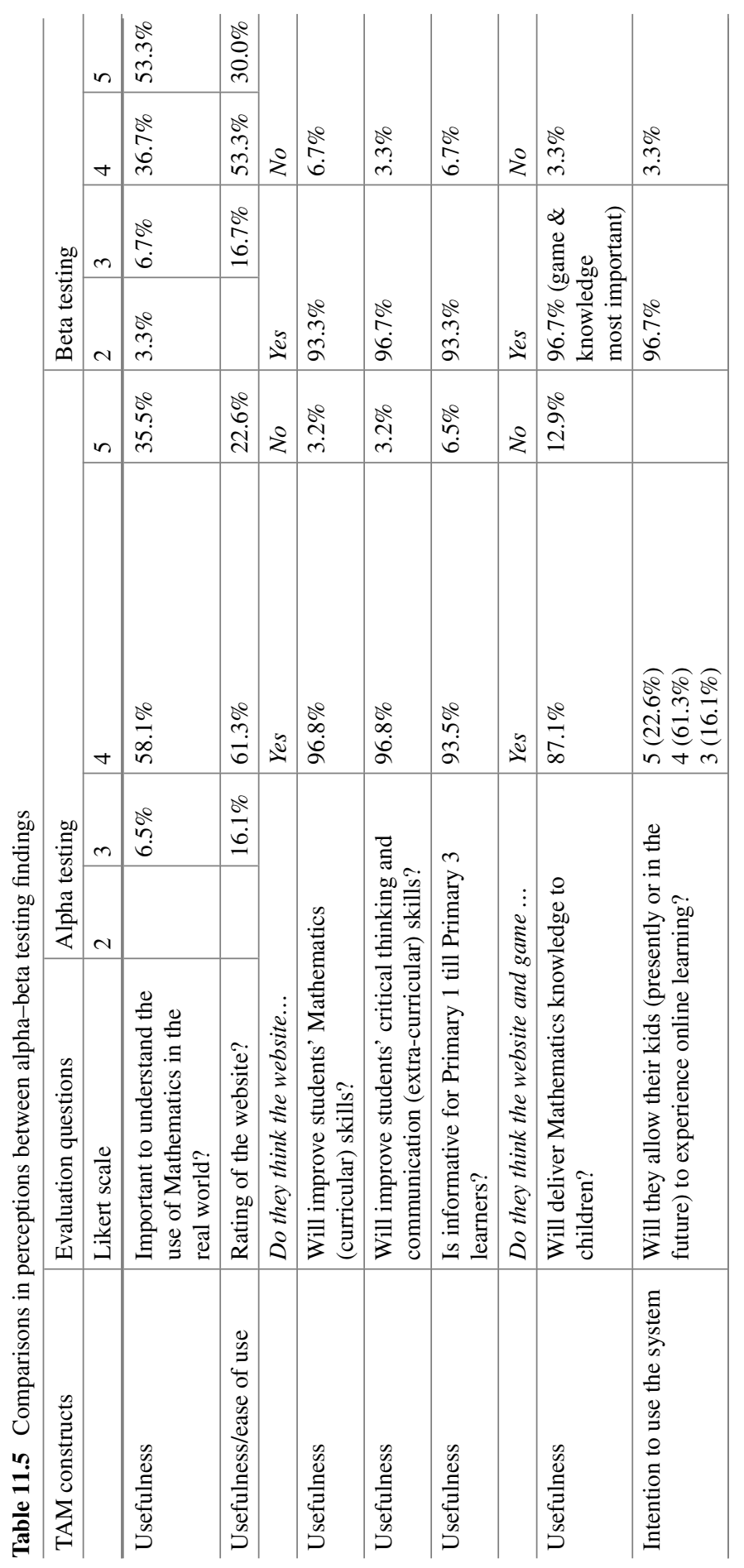


Table 11.6 Expectations for future Website and Game development

\begin{tabular}{l|l}
\hline \multicolumn{2}{l}{ What do you expect from the website and game? } \\
\hline Alpha testing & Beta testing \\
\hline $\begin{array}{l}\text { Critical thinking skills in solving Math problems } \\
(2)\end{array}$ & To learn and advance in Mathematics \\
\hline $\begin{array}{l}\text { Knowledgeable and fun, enable the user to } \\
\text { watch and learn with fun, something interesting, } \\
\text { strategy game }\end{array}$ & $\begin{array}{l}\text { To improve my knowledge of Mathematics } \\
\text { and have fun. An interesting game with } \\
\text { Mathematics }\end{array}$ \\
\hline $\begin{array}{l}\text { Improve design } \\
\begin{array}{l}\text { Add more things, more exercise, more } \\
\text { worksheets, more pictures, and give answers }\end{array}\end{array}$ & $\begin{array}{l}\text { More design, pretty user interface } \\
\text { calculation according to standard of } \\
\text { difficulty }\end{array}$ \\
\hline & $\begin{array}{l}\text { It is not the content of the website. Instead, it } \\
\text { is the intention of the person using the } \\
\text { website/game }\end{array}$ \\
\hline
\end{tabular}

\subsection{Significance}

The role of technology in inquiry-based, student-centered learning is not always easy. The crux of student-centered learning framework is the derivation of principles, and this is more likely to happen if teachers themselves teach using a principle-based approach. Various studies such as Song and Looi (2012) and Kong and Song's (2013) studies have confirmed this reasoning.

The significance of our study lies in:

(a) Validating our design and obtaining technology acceptance via iterative cycles of awareness creation toward the usefulness of each design component. Acceptance of the design and technology implies that the Website content can inspire children's interest in learning Mathematics and that the qualities inspired by Mathematics such as the power of reasoning, creativity, critical thinking, problemsolving ability, and effective communication skills can be more easily developed in the future. This is in line with Chan's (2010) compelling, sustainable, and "disseminable" experimental digital classroom and MIT's Scratch approach.

(b) Contributing to the larger body of research on motivational orientations such as the prominent self-directed studies by Lao, Cheng, Huang, Ku, Chan (2017). Our study is aimed at developing epistemic agency based on the Learning Sciences and the Institute of Electrical and Electronic Engineering's (IEEE) thrust, building on past work by Lee and Wong (2017). Although our study is slightly different from that of Lao, Cheng, Huang, Ku, Chan's (2017) in terms of epistemologies/orientations, we hope our study can help contribute to the larger extant work. It may also be interesting to work with Chien, Chen and Chan (2017). 


\subsection{Conclusion}

Parents should start introducing Mathematical concepts to their children from young. In order to attract their attention to learning, methods of teaching and learning should be fun as it might be difficult to gain their interest once they have lost it.

The design of this study has incorporated Brennan and Resnick's (2012) computational perspective, computational practice, computational concepts, and KM approaches. CT-based Mathematics provides a direct link to principles. Hence, it is important to develop such skills. Our fun Computational Thinking-Knowledge Management (CT-KM) design and approach follow an inquiry-student-centered learning framework. The role of technology in terms of exploration, construction as well as communication in inquiry-student-centered learning parallels that of KM's knowledge acquisition, sharing, creation, and dissemination.

To validate our designs for the learning of Mathematics and CT, the opinions and feedback of users from different age groups are obtained through user testings and questionnaires. Although the target users of the Website are primary school students, comments from young adults, adults, and senior citizens are taken into consideration as they are the stakeholders who will influence and encourage the younger children.

Our findings indicate that the perceptions of different stakeholders toward CTbased Mathematics learning have improved as the Website provides different ways of learning to suit different contexts and needs. It is our hope that schools in Malaysia will also see more creative outcomes to problems. Furthermore, we hope that by enabling students to create, share, and discuss fun-based problems for others to solve, they would feel encouraged to create and share knowledge, and eventually, have a greater appreciation of Mathematics and CT.

Acknowledgements The first author would like to thank Prof. Tak-Wai Chan for his question what is Mathematics learning? while she was a Faculty at the Graduate Institute of Network Technology, National Central University, Taiwan, ROC. Thanks also to MIT's Scratch for paving the way, the 2017 Computational Thinking conference for highlighting what CT is and Dr. K. Daniel Wong for prior collaboration on design thinking and CT.

\section{References}

Abelson, H. (2012). From computational thinking to computational values. In Special Interest Group on Computer Science Education (SIGCSE) (pp. 239-240).

Adkins, S. S. (2016). The 2016-2021 Worldwide game-based learning market. Ambient Insight. In Serious Play Conference. Retrieved April 30, 2017.

American Academy of Child and Adolescent Psychiatry. (2015). Video Games and Children: Playing with Violence, Retrieved April 12, 2017, from http://www.aacap.org/AACAP/Families_ and_Youth/Facts_for_Families/FFF-Guide/Children-and-Video-Games-Playing-with-Violence091.aspx.

Biswas, C. (2015). The importance of Maths in everyday life. Guwahati News. Retrieved April 15, 2017, from http://timesofindia.indiatimes.com/city/guwahati/The-importance-of-maths-ineveryday-life/articleshow/48323205.cms. 
Brennan, K., \& Resnick, M. (2012). New frameworks for studying and assessing the development of computational thinking. In Proceedings of the 2012 Annual Meeting of the American Educational Research.

Chan, T. W. (2010). How East Asian classrooms may change over the next 20 years. 25th Anniversary Special Issue of Journal of Computer-Assisted Learning, January, 2010.

Chien, T. C., Chen, Z. H., \& Chan, T. W. (2017). Exploring long-term behavior patterns in a book recommendation system for reading. Educational Technology \& Society, 20(2), 27-36.

Christopher, D. (2015). The negative effects of video game addiction. Livestrong.com. Retrieved April 12, 2017, from http://www.livestrong.com/article/278074-negative-effects-of-video-gameaddiction.

Computationalthinkingcourse.withgoogle.com (2017). What is computational thinking? Computational Thinking for Educators. Retrieved October 27, 2017, from https:// computationalthinkingcourse.withgoogle.com/unit.

Ertmer, P. A., Ottenbreit-Leftwich, A. T., Sadik, O., Sendurur, E., \& Sendurur, P. (2012). Teacher beliefs and technology integration practices: A critical relationship. Computers \& Education, $59(2), 423-435$.

Frappaolo, C. (2006). Knowledge management (2nd ed.). New York: Capstone Publishing.

Jashapara, A. (2011). Knowledge management: An integrated approach. London: Pearson.

Kazimoglu, C., Kiernan, M., Bacon, L., \& MacKinnon, L. (2012). Learning programming at the computational thinking level via digital game-play. Procedia Computer Science, 9, 522-531.

Kong, S. C. (2019). Partnership among schools in e-Learning implementation: Implications on elements for sustainable development. Educational Technology \& Society, 22(1), $28-43$.

Kong, S. C., \& Song, Y. (2013). A principle-based pedagogical design framework for developing constructivist learning in a seamless learning environment: A teacher development model for learning and teaching in digital classrooms. British Journal of Educational Technology, 44(6), 209-212.

Koster, R. (2004). Theory of fun for game design. New York: O'Reilly Media.

Lao, A. C. C., Cheng, H. N., Huang, M. C., Ku, O., \& Chan, T. W. (2017, Jan). Examining motivational orientation and learning strategies in Computer-Supported Self-Directed Learning (CSSDL) for Mathematics: The perspective of intrinsic and extrinsic goals. Journal of Educational Computing Research, 54(8), 1168-1188.

Lee, C. S., Wong, J. W., \& Ee, P. Y. (2017). Gamified mathematics practice: Designing with ecommerce and computational concepts. In International Conference on Computational Thinking, July 13-15, 2017, Hong Kong.

Lee C. S. \& Wong K. D. (2017). An entrepreneurial narrative media-model framework for knowledge building and open co-design. In IEEE SAI Computing, July 18-20, 2017, London, UK.

Maier, R. (2010). Knowledge management systems: Information and communication technologies for knowledge management (3rd ed.). Heidelberg: Springer.

Nonaka, I., \& Takeuchi, H. (1991). The knowledge-creating company: How Japanese companies create the dynamics of innovation. Harvard Business Review, 69, 96-104.

Resnick, M. (2007). Sowing the seeds for a more creative society. In Learning and leading with technology, December-January, 2007-2008, 18-22.

Snalune, P. (2015). The benefits of computational thinking. ITNOW, 57(4), 58-59. Retrieved November 4, 2017, from http://www.bcs.org/content/ConWebDoc/55416.

Song, Y., \& Looi, C. K. (2012). Linking teacher beliefs, practices and student inquiry-based learning in a CSCL environment: A tale of two teachers. International Journal of Computer-Supported Collaborative Learning, 7(1), 129-159.

Togyer, J., \& Wing, M. J. (2017). Research notebook: Computational thinking-what and why? Carnegie Mellon School of Computer Science. Retrieved November 2, 2017, from https://www. cs.cmu.edu/link/research-notebook-computational-thinking-what-and-why.

Venkatesh, V., \& Davis, F. D. (2000). A theoretical extension of the technology acceptance model: Four longitudinal field studies. Management Science, 46(2), 186-204. 
Weintrop, D., Holbert, N. S., Horn, M., \& Wilensky, U. (2016). Computational thinking in constructionist video games. International Journal of Game-Based Learning, 6(1), 1-17. Retrieved November 2, 2017 from http://ccl.northwestern.edu/2016/WeintropHolbertHornWilensky2016. pdf.

Wing, J. (2006). Computational thinking. Communications of the ACM, 49(3), 33-35.

Open Access This chapter is licensed under the terms of the Creative Commons Attribution 4.0 International License (http://creativecommons.org/licenses/by/4.0/), which permits use, sharing, adaptation, distribution and reproduction in any medium or format, as long as you give appropriate credit to the original author(s) and the source, provide a link to the Creative Commons license and indicate if changes were made.

The images or other third party material in this chapter are included in the chapter's Creative Commons license, unless indicated otherwise in a credit line to the material. If material is not included in the chapter's Creative Commons license and your intended use is not permitted by statutory regulation or exceeds the permitted use, you will need to obtain permission directly from the copyright holder. 